\title{
Pengaruh Kecepatan Fluida dan Jarak antar Zig Zag Filter Foam Filler terhadap Efektifitas Cooling Tower
}

\author{
Andrea Setiawan ${ }^{1}$, A'rasy Fahruddin $^{2}$ \\ Email corresponding author: arasy.fahruddin@umsida.ac.id \\ ${ }^{1,2}$ Teknik Mesin, Universitas Muhammadiyah Sidoarjo, Jl. Mojopahit 666 B Sidoarjo, Indonesia
}

Article history: Received: 24 Januari 2020 | Revised: 22 Juni 2021 | Accepted: 28 Juni 2021

\begin{abstract}
This study aims to determine the effect of fluid velocity and the distance between the zig zag filter on the cooling tower by varying the distance between the zig zag bio filter foam. In this study, bio filter foam material was used in a zig zg shape using wire mesh where the distances tested were $5 \mathrm{~cm}, 10 \mathrm{~cm}$, and $15 \mathrm{~cm}$. Then the water is heated using a heater until it reaches a temperature of $40^{\circ} \mathrm{C}$ and then the water is flowed up by a pipe using a pump and removed using a nozzle, then the hot water will go down to the reservoir by passing the bio filter foam arrangement that has been installed with a distance of $5 \mathrm{~cm}, 10 \mathrm{~cm}$, and $15 \mathrm{~cm}$. Where there is also a drain valve that is done, namely a closed faucet and also an open kran and fully open faucet. A good cooling value is shown at a distance of $5 \mathrm{~cm}$ where the average temperature difference is $3.47 \mathrm{C}$ and the effectiveness is $26.67 \%$.
\end{abstract}

Keywords - Bio filter foam; cooling tower; temperature; cooling effectiveness

Abstrak. Penelitian ini bertujuan untuk mengetahui pengaruh kecepatan fluida dan jarak antar zig zag filter pada cooling tower dengan memvariasikan jarak antar zig zag busa bio filter. Pada penelitian ini menggunakan bahan busa bio filter yang di bentuk zig zg dengan menggunakan kawat jaring di mana jarak yang di uji adalah $5 \mathrm{~cm}, 10 \mathrm{~cm}$, dan juga $15 \mathrm{~cm}$. Kemudian air dipanaskan dengan menggunakan pemanas hingga mencapai suhu $40^{\circ} \mathrm{C}$ dan selanjutnya air tersebut di alirkan ke atas dengan pipa menggunakan pompa dan di keluarkan dengan menggunakan nozel, selanjutnya air panas tersebut akan turun ke bak penampung dengan melewati susunan busa bio filter yang sudah terpasang dengan jarak $5 \mathrm{~cm}, 10 \mathrm{~cm}$, dan $15 \mathrm{~cm}$. Dimana terdapat juga kran pembuangan yang di lakukan yaitu kran tertutup dan juga kran terbuka 1/2 dan terbuka full. Nilai pendinginan yang baik ditunjukan pada jarak $5 \mathrm{~cm}$ dimana dihasilkan beda temperatur rata - rata $3,47^{\circ} \mathrm{C}$ dan efektifitas sebesar $26,67 \%$.

Kata Kunci - Busa bio filter; cooling tower; temperatur; efektifitas pendinginan

\section{Pendahuluan}

Cooling tower adalah alat penukar kalor yang memanfaatkan udara lingkungan untuk mendinginkan air panas. Air perlu didinginkan agar siap digunakan kembali sebagai pendingin [1]. Air ini biasa digunakan untuk pendingin pada berbagai industri diantaranya pada kondenser kilang minyak [2], pendingin pada proses molding plastik [3], pendingin pada industri manufaktur [4], hingga pendingin pada siklus uap dan pembangkit tenaga listrik [5], [6]. Cooling tower memiliki keunggulan sebagai sistem pendingin pada berbagai industri karena pendinginan dilakukan dengan kontak langsung antara air panas dengan udara lingkungan sehingga panas lebih maksimal dipindahkan ke udara lingkungan. Semakin besar udara mengalir ke dalam cooling tower, semakin besar kapasitas pendinginan [7].

Berbagai cara digunakan untuk meningkatkan efektifitas cooling tower. Salah satunya adalah dengan memodifikasi bahan maupun susunan filler pada cooling tower. Filler pada cooling tower berfungsi sebagai penahan aliran air agar menghasilkan waktu kontak yang lebih lama dengan udara lingkungan sekaligus sebagai media untuk memperluas area kontak air dengan udara [8]. Dengan filler berbentuk pori-pori atau serat-serat maka akan terbentuk luas area kontak yang lebih besar sehingga perpindahan panas konveksi akan lebih baik. Selain itu susunan filler juga akan mempengaruhi aliran air dan udara sekaligus waktu kontak. Semakin rapat susunan filler tentu akan menambah waktu kontak, tetapi akan menghasilkan pressure drop yang lebih besar [9]. Eky dan Gatot (2019) telah meneliti tentang penggunaan filler dengan variasi bentuk filler yaitu lurus, zig-zag, dan gelombang [10]. Hasil penelitiannya menunjukkan bahwa bentuk gelombang dan zig zag menghasilkan efektifitas yang lebih baik dibanding bentuk lurus.

Filter foam merupakan salah satu material yang dapat digunakan sebagai filler pada cooling tower, karena memiliki banyak pori-pori dan memiliki kelebihan mampu dicuci dan digunakan kembali. Akan tetapi penggunaan filter foam masih perlu diteliti untuk menentukan susunan pemasangannya pada cooling tower. Pada penelitian ini dilakukan pengujian penggunaan filter foam sebagai bahan alternatif filler cooling tower dengan pemasangan bersusun dengan variasi jarak zig zag untuk mengetahui pengaruhnya terhadap performa cooling tower. Bentuk zig zag dipilih karena lebih mudah dalam pembuatan dan pengaturan jaraknya. 


\section{METODE}

Penelitian ini menggunakan suatu metode pendekatan yaitu metode eksperimen. Pengujian dilakukan dengan menggunakan prototipe cooling tower induced draft skala laboratorium dengan ukuran $120 \times 40 \times 40 \mathrm{~cm}^{3}$, dengan skema instalasi seperti ditunjukkan pada Gambar 1. Busa bio filter digunakan untuk material pengisi pada cooling tower, dan dibentuk zig-zag dengan mesh kawat. Dalam penelitian ini variable bebasnya adalah Jarak antar zig zag filter foam: $5 \mathrm{~cm}, 10 \mathrm{~cm}$, dan $15 \mathrm{~cm}$. Seperti ditunjukkan pada Gambar 2. Serta debit air panas divariasikan dengan mengatur bukaan kran pembuangan: kran tertutup, kran pembuangan terbuka 1/2, dan kran pembuangan terbuka full. Dimana semakin besar bukaan pembuangan, maka semakin kecil debit air panas masuk cooling tower.

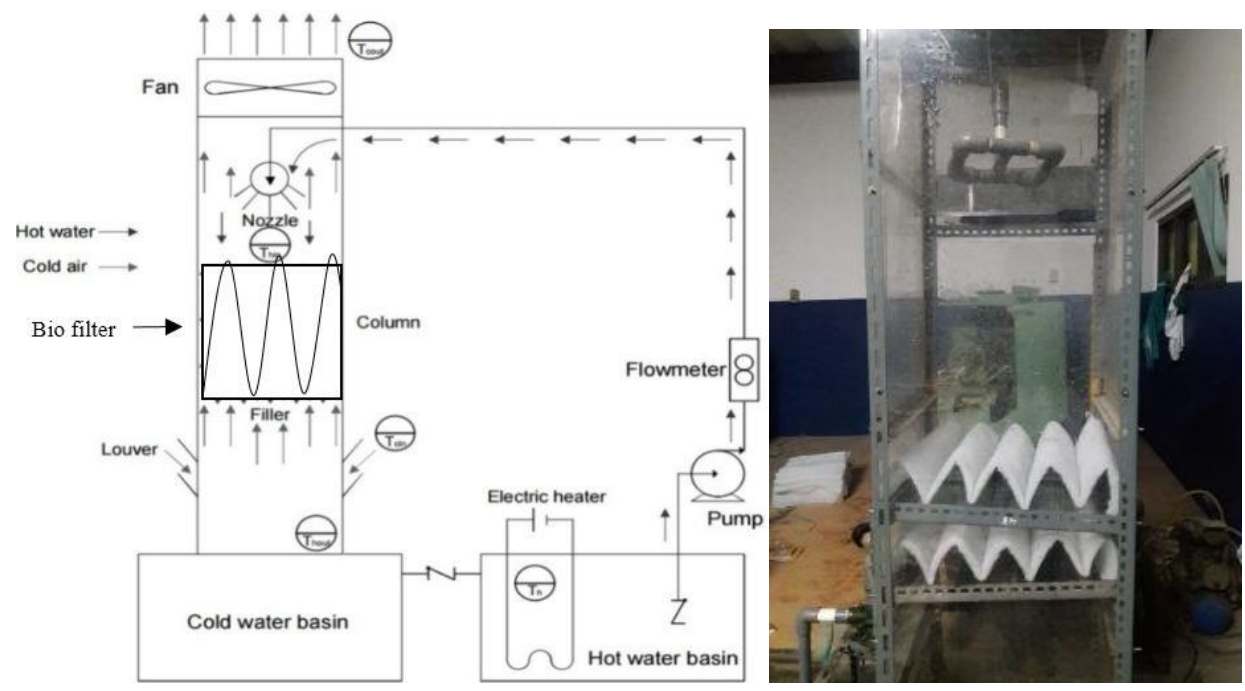

Gambar 1. Instalasi Pengujian [10]

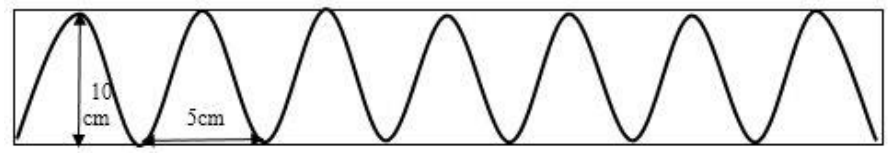

a) Jarak zig zag $5 \mathrm{~cm}$

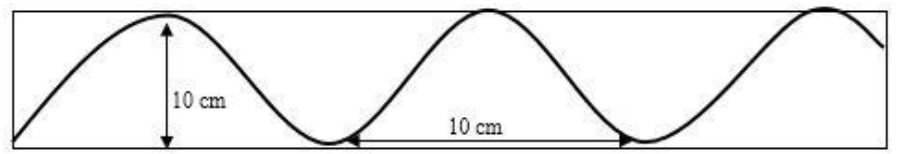

b) Jarak zig zag $10 \mathrm{~cm}$

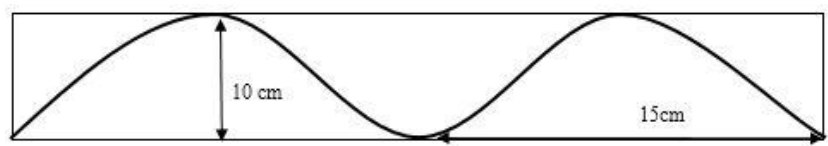

c) Jarak zig zag $15 \mathrm{~cm}$

Gambar 2. Variasi jarak zig-zag pengisi cooling tower

Dalam penelitian ini variable terikatnya adalah berupa beda temperatur, kapasitas pendinginan, dan efektifitas pendinginan cooling tower. Sedangkan variabel terkontrol berupa debit udara dan temperatur udara masuk yang diasumsikan konstan. Kapasitas pendinginan dihitung dengan persamaan:

$$
Q=m \cdot C_{p} \cdot d T
$$

Dimana $d T$ merupakan beda temperatur pada fluida air masuk dan keluar. Sedangkan efektifitas pendinginan dihitung dengan persamaan:

$$
\eta=\frac{m \cdot C p \cdot d T}{(m \cdot C p)_{\min } \cdot d T_{\max }}
$$

Dimana $d T_{\max }$ adalah beda temperatur antara air masuk dan udara masuk. 


\section{Hasil dan Pembahasan}

Pengujian pertama yaitu kran tertutup rapat dan bak yang terisi air dipanaskan dengan elemen penukar kalor hingga tercapai suhu $40{ }^{\circ} \mathrm{C}$, kalau sudah tercapai kemudian pompa di hidupkan lalu air akan naik ke atas dan keluar di nozel dan selanjutnya lewat di sela - sela busa bio filter, selanjutnya pompa dimatikan dan cek suhu air yang berada di bak penyimpanan di bagian bawah cooling tower, setelah itu tunggu 20 detik dan di lakukan pengecekan suhu air, pengecekan dilakukan sebanyak 3 kali. Selanjutnya dilakukan penelitian dengan cara yang sama tetapi kran tertutup $1 / 2$ dan selanjutnya terbuka full.

Selanjutnya melakukan pengamatan, di mana hasil rata - rata uji pendinginan terkecil yaitu $36,53{ }^{\circ} \mathrm{C}$ yang di hasilkan dari busa bio filter yang jarak zig zag $5 \mathrm{~cm}$ dan tinggi $10 \mathrm{~cm}$ pada saat kran terbuka, nilai tersebut lebih rendah jika di bandingkan dengan kran yang tertutup rapat yaitu dengan data $37,17{ }^{\circ} \mathrm{C}$. Sedangkan angka rata - rata uji pendinginan terbesar pada uji coba ini ada $38,93{ }^{\circ} \mathrm{C}$ yang di hasilkan dari busa bio filter yang jarak zig zag $15 \mathrm{~cm}$ dan tinggi $10 \mathrm{~cm}$ pada saat kran tertutup.

Gambar 4 menunjukan nilai rata - rata yang dihasilkan dari penelitian yang dilakukan, dimana temperatur air keluar yang terendah yaitu pada jarak zig zag $5 \mathrm{~cm}$, sebesar $36,5^{\circ} \mathrm{C}$ pada posisi bukaan kran pembuangan full. Pada bukaan kran pembuangan full debit air yang masuk ke cooling tower paling kecil. Pada jarak $5 \mathrm{~cm}$ temperatur air keluar terendah dibanding jarak $10 \mathrm{~cm}$ dan $15 \mathrm{~cm}$, karena pada jarak $5 \mathrm{~cm}$ maka jumlah zig zag akan lebih banyak dibandingkan dengan jarak zig zag yang $10 \mathrm{~cm}$ dan $15 \mathrm{~cm}$, sehingga air dari nozel menuju bak penampung akan lebih lama kontak dengan udara pendingin. hasil penelitian di atas maka cooling tower yang baik pada saat air panas mengalir dari nozel dengan posisi kran pembuangan terbuka full di bandingkan dengan yang tertutup atau pun terbuka $1 / 2$, karena didapatkan hasil pada saat terbuka full yaitu $36,5{ }^{\circ} \mathrm{C}$ di jarak zig zag $5 \mathrm{~cm}$ dibandingakan dengan pada saat kran tertutup yaitu $37,2{ }^{\circ} \mathrm{C}$ di jarak zig zag $5 \mathrm{~cm}$, dan di kran pembuangan terbuka $1 / 2$ yaitu hasil nya $36,9{ }^{\circ} \mathrm{C}$ pada jarak zig zag $5 \mathrm{~cm}$.

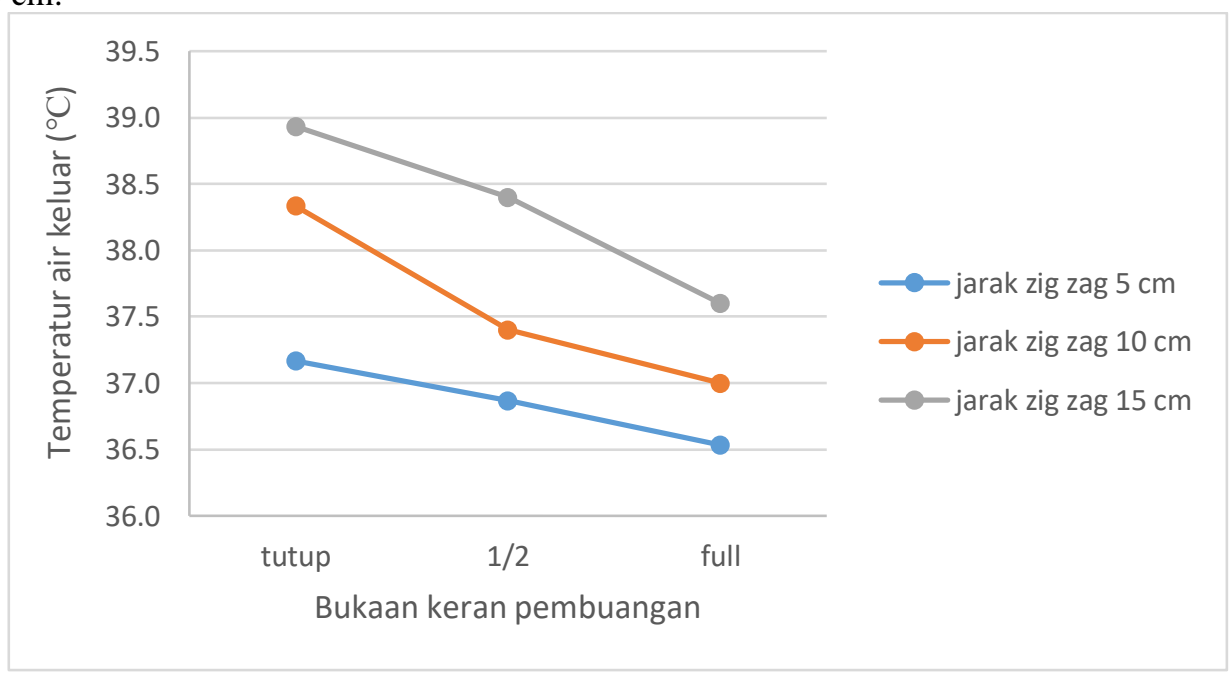

Gambar 4. Grafik temperatur air keluar rata - rata

Pada Gambar 5 dapat dilihat bahwa selisih temperatur yang tinggi berada di jarak zig zag yang $5 \mathrm{~cm}$ hingga mencapai $3,47^{\circ} \mathrm{C}$ di banding dengan yang $10 \mathrm{~cm}$ dan juga $15 \mathrm{~cm}$. Dapat dilihat pula bawasanya kran pembuangan mempengaruhi juga selisih temperatur di mana kran posisi terbuka full memiliki selisih temperatur yang tinggi pada jarak zig zag $5 \mathrm{~cm}$ yaitu $3,47^{\circ} \mathrm{C}$, dibandingkan dengan posisi kran pembuangan yang tertutup dan $1 / 2$ terbuka di mana memiliki hasil selisih temperatur $2,83^{\circ} \mathrm{C}$ pada jarak zig zag $5 \mathrm{~cm}$ pada saat kran tertutup. Selisih temperatur nilainya semakin tinggi saat bukaan buang makin tinggi atau debit aliran semakin rendah. Hal ini dikarenakan makin lamanya waktu kontak antara fluida panas dengan fluida pendingin [8]. 


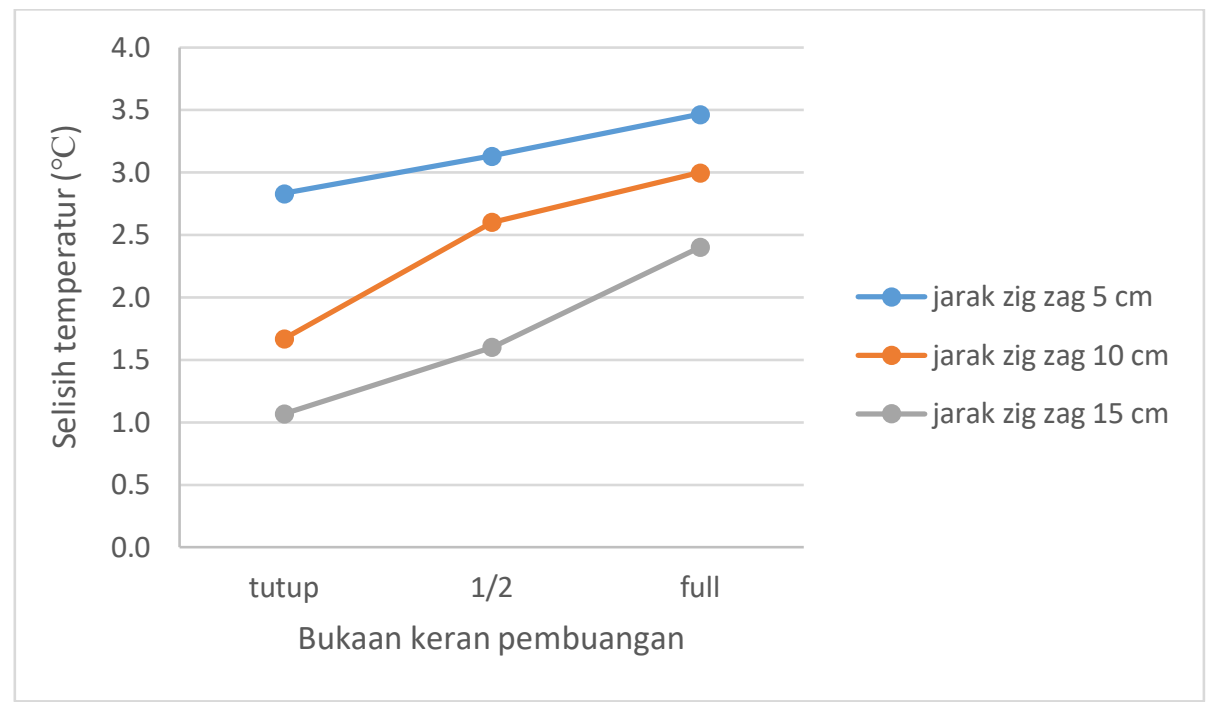

Gambar 5. Grafik selisih temperatur

Dari Gambar 6 terlihat bahwa kapasitas pendinginan pada jarak $5 \mathrm{~cm}$ memiliki hasil yang tertinggi yaitu 1151,99 watt dibanding dengan jarak $10 \mathrm{~cm}$ dan juga $15 \mathrm{~cm}$. Sedangkan yang terendah yaitu 433,69 watt pada jarak $15 \mathrm{~cm}$. Sehingga jarak zig zag yang baik pada kapasitas pendinginannya adalah jarak yang $5 \mathrm{~cm}$. Dan juga hasil percobaan di atas dimana kapasitas pendinginan yang tinggi pada posisi kran tertutup yang mempunyai hasil 1151,99 watt pada jarak $5 \mathrm{~cm}$ di bandingkan dengan kran pembuangan terbuka full ataupun $1 / 2$ terbuka, di mana hasil 653,89 watt pada saat kran pembuangan terbuka full pada jarak zig zag $5 \mathrm{~cm}$.

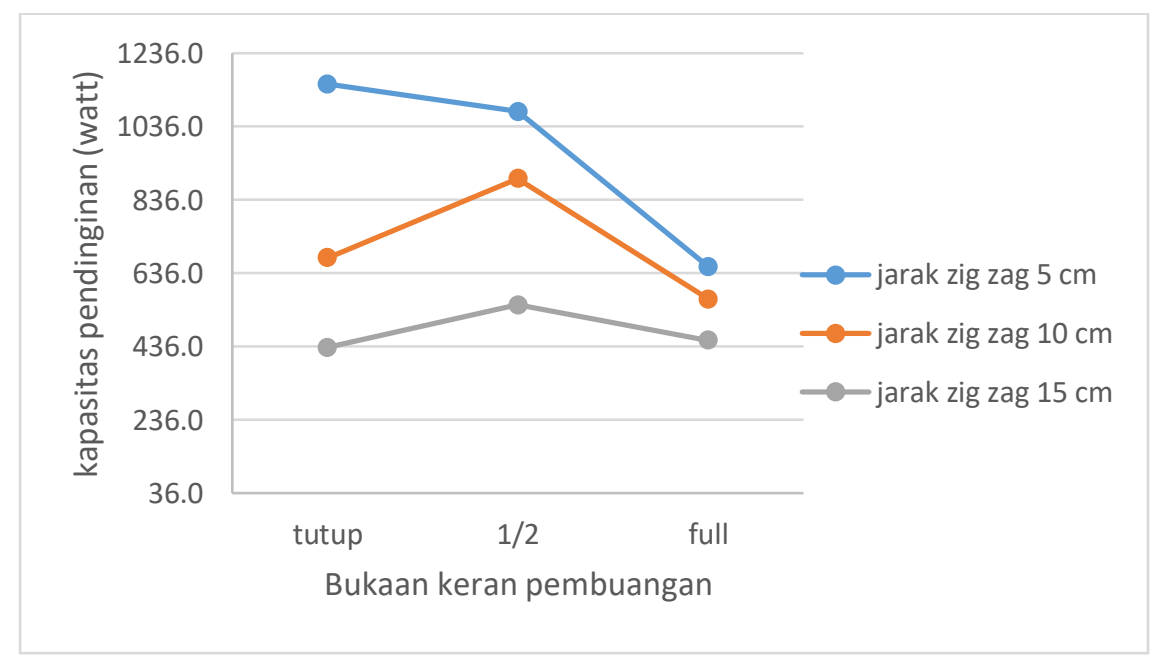

Gambar 6. Grafik kapasitas pendingin

Dari Gambar 7 dapat dilihat bahwa efektifitas pendinginan pada jarak zig zag yang $15 \mathrm{~cm}$ sangat rendah nilai nya dibanding jarak $10 \mathrm{~cm}$ dan juga $5 \mathrm{~cm}$, bisa dilihat pada grafik di mana yang abu - abu jarak $15 \mathrm{~cm}$ (paling bawah) sedangkan yang biru jarak $5 \mathrm{~cm}$ (paling atas), yang memili hasil 8,21\% pada jarak zig zag $15 \mathrm{~cm}$ dan yang $5 \mathrm{~cm}$ memiliki hasil 26,67 \%. Sedangkan posisi kran pada percobaan efektifitas pendinginan yang tinggi yaitu posisi kran pembuangan terbuka full yang mempunyai nilai $26,67 \%$, sedangkan pada posisi kran tertutup memiliki nilai $21,79 \%$ pada jarak zig zag $5 \mathrm{~cm}$. 


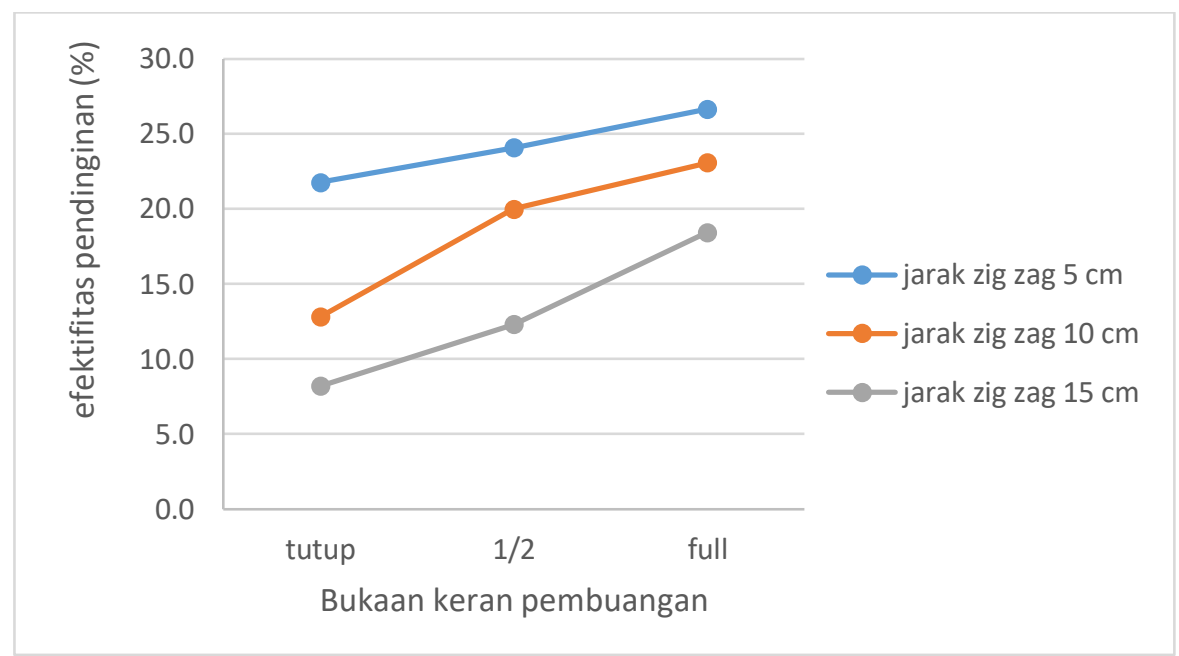

Gambar 7. Grafik efektifitas pendinginan

Dari Gambar 8 bisa dilihat bahwa kapasitas pendinginan maupun efektifitas pendinginan semakin kecil dengan jarak zig-zag yang semakin besar. Dimana kapasitas pendinginan merupakan besar kalor yang dapat dipindah dari air panas ke udara pendingin, sedangkan efektifitas pendinginan merupakan perbandingan kapasitas pendinginan aktual dengan kapasitas pendinginan maksimum yang seharusnya bisa dicapai secara teoritis. Nilai kapasitas pendinginan tertinggi adalah 1151,99 watt pada jarak zig zag $5 \mathrm{~cm}$ sedangkan nilai efektifitas pendinginan tertinggi sebesar 26,67\% juga pada jarak zig zag $5 \mathrm{~cm}$. Dari kesimpulan jarak antar zig zag di mana jarak $5 \mathrm{~cm}$ memiliki nilai yang tinggi dibanding dengan yang $10 \mathrm{~cm}$ dan $15 \mathrm{~cm}$ pada kapasitas pendinginan maupun efektifitas pendinginan. Sedangkan nilai kapasitas pendinginan pada jarak $15 \mathrm{~cm}$ yaitu 452,69 watt dan efektifitas pendinginannya 18,46\%.

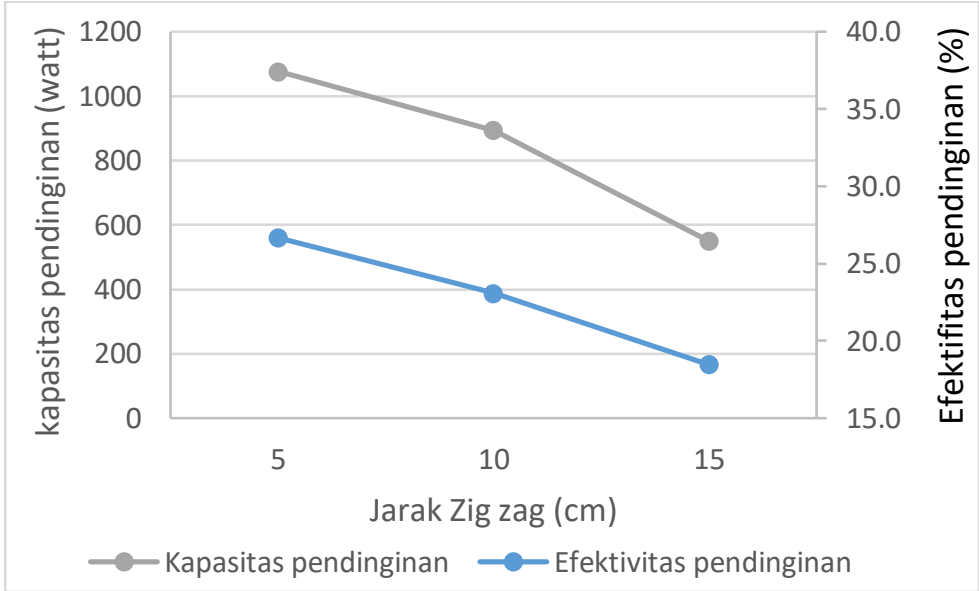

Gambar 8. Grafik perbedaan kapasitas pendinginan dan efektifitas pendinginan

\section{KESIMPULAN}

Data hasil penelitian yang di peroleh bawasannya jarak zig zag yang $5 \mathrm{~cm}$ sangatlah baik dalam pendinginan dibandingkan dengan jarak zig zag $10 \mathrm{~cm}$ dan juga $15 \mathrm{~cm}$, karena semakin sempit jarak zig zag maka semakin banyak pula zig zag yang di hasikan, yang dapat menyebabkan hambatan air panas yang turun ke bak penampung. Dengan jarak zig zag $10 \mathrm{~cm}$ dan $15 \mathrm{~cm}$, air panas yang mengalir ke bak penampung akan tertahan tetapi kurang maksimal dibanding yang $5 \mathrm{~cm}$ jarak zig zagnya. Selain itu, jarak zig-zag yang lebih rapat akan menghasilkan luas permukaan yang lebih besar. Semakin lama air panas jatuh dan semakin luas permukaan kontak dengan udara pendingin maka semakin besar panas yang dapat dipindahkan. Demikian pula debit aliran yang rendah akan menghasilkan temperatur output yang lebih dingin sehingga menghasilkan efektifitas pendinginan terbaik. Akan tetapi debit yang rendah menghasilkan kapasitas pendinginan yang kurang baik, kapasitas pendinginan terbaik terjadi pada debit menengah. 


\section{UCAPAN TERIMA KASIH}

Terima kasih kepada labolatorium Teknik Mesin UMSIDA yang telah memberikan fasilitas untuk melaksanakan penelitian ini, tanpa adanya labolatorium Teknik Mesin UMSIDA penelitian ini tidak akan berjalan dengan baik.

\section{REFERENSI}

[1] S. Yulianto and A. Urbiantoro, "Perancangan Cooling Tower Untuk Alat Penukar Kalor Shell and Tube Kapasitas Skala Laboratorium,” Sintek, vol. 7, no. 1, pp. 1-11, 2013.

[2] A. S. Anugrah, F. A. Firmansyah, R. A. Ilhamsyah, and M. F. Umam, "Analisis Kinerja Natural Draft Cooling Tower di Unit Kilang Pusat Pengembangan Sumber Daya Manusia Minyak dan Gas Bumi,” Maj. Ilm. Swara Patra, vol. 11, no. 1, pp. 1-13, 2021.

[3] A. I. Ramadhan, E. Diniardi, and M. Daroji, "Analisa Penyusutan Produk Plastik di Proses Injection Molding Menggunakan Media Pendingin Cooling Tower dan Udara dengan Material Polypropylene," JRST J. Ris. Sains Dan Teknol., vol. 1, no. 2, pp. 65-74, 2017.

[4] M. T. Wirawan, "Sistem Otomatisasi Pompa Air Water Cooling Tower Menggunakan Mikrokontroler Arm STM32F4 Di PT. Indospring Tbk," E-Link J. Tek. Elektro dan Inform., vol. 15, no. 2, p. $23,2020$.

[5] Y. Handoyo, “Analisis Performa Cooling Tower LCT 400 Pada P.T. XYZ, Tambun Bekasi,” J. Ilm. Tek. Mesin, vol. 3, no. 1, pp. 38-52, 2015.

[6] A. A. Melkias, "Analisa Performa Pada Cooling Tower Jenis Mechanical Draft Crossflow," J. Energi, vol. 10, no. 1, pp. 24-28, 2020.

[7] Sarjito and T. W. B. Riyadi, "A parametric study of wind catcher model in a typical system of evaporative cooling tower using CFD," Appl. Mech. Mater., vol. 660, no. October, pp. 659-663, 2014.

[8] A. Fahruddin, M. Muslimin, G. D. Susilo, and A. Akbar, "Experimental study effect of diameter and number of spray nozzle holes on counterflow cooling tower to improve cooling effectiveness," in MATEC Web of Conferences, 2018.

[9] R. Firyanto, "Distribusi udara dalam water cooling tower," Momentum, vol. 1, no. 2, pp. 1-4, 2005.

[10] E. Novianarenti and G. Setyono, "Peningkatan Performansi Cooling Tower Tipe Induced Draft Counter Flow Menggunakan Variasi Bentuk Filler," R.E.M (Rekayasa Energi Manufaktur) J., vol. 4, no. 1, pp. $17-$ 26, 2019. 